\title{
Statistics Provide Guidance for Indigenous Organic Carbon Detection on Mars Missions
}

\author{
Mark A. Sephton and Jonathan N. Carter
}

\begin{abstract}
Data from the Viking and Mars Science Laboratory missions indicate the presence of organic compounds that are not definitively martian in origin. Both contamination and confounding mineralogies have been suggested as alternatives to indigenous organic carbon. Intuitive thought suggests that we are repeatedly obtaining data that confirms the same level of uncertainty. Bayesian statistics may suggest otherwise. If an organic detection method has a true positive to false positive ratio greater than one, then repeated organic matter detection progressively increases the probability of indigeneity. Bayesian statistics also reveal that methods with higher ratios of true positives to false positives give higher overall probabilities and that detection of organic matter in a sample with a higher prior probability of indigenous organic carbon produces greater confidence. Bayesian statistics, therefore, provide guidance for the planning and operation of organic carbon detection activities on Mars. Suggestions for future organic carbon detection missions and instruments are as follows: (i) On Earth, instruments should be tested with analog samples of known organic content to determine their true positive to false positive ratios. (ii) On the mission, for an instrument with a true positive to false positive ratio above one, it should be recognized that each positive detection of organic carbon will result in a progressive increase in the probability of indigenous organic carbon being present; repeated measurements, therefore, can overcome some of the deficiencies of a less-thandefinitive test. (iii) For a fixed number of analyses, the highest true positive to false positive ratio method or instrument will provide the greatest probability that indigenous organic carbon is present. (iv) On Mars, analyses should concentrate on samples with highest prior probability of indigenous organic carbon; intuitive desires to contrast samples of high prior probability and low prior probability of indigenous organic carbon should be resisted. Key Words: Mars-Life-detection instruments - Search for Mars' organics-ContaminationBiosignatures. Astrobiology 14, 706-713.
\end{abstract}

\section{Introduction}

T HE SEARCH FOR LIFE on Mars involves instrument-based attempts to detect organic matter. One current example of the organic detection approach is provided by the Mars Science Laboratory (MSL) mission that is operating on the Red Planet. MSL data from the Rocknest eolian deposit (Leshin et al., 2013) and Yellowknife Bay mudstone (Ming et al., 2014) reveal the evolution of oxygen at the same temperatures as chlorine species, suggesting the thermal decomposition of perchlorate salts. Some chlorine was contained within a series of chlorohydrocarbons at levels that exceeded instrumental background. It is suggested that perchlorate chlorine has combined with organic carbon from a terrestrial derivatizing agent carried to Mars with the spacecraft, but martian or meteoritic sources of organic carbon, which can be collectively termed indigenous, are also pos- sibilities. The uncertainty surrounding the source of carbon ensures that the confident detection of indigenous organic carbon on Mars remains elusive. Reinterpretation of Viking data (Navarro-González et al., 2010) suggests that the MSL responses may not be the first time that organic matter has been detected on Mars with incomplete confidence in the source of the carbon. Chlorohydrocarbons were also detected at both Viking landing sites at levels that exceeded instrumental background. Contemporary interpretations assigned the chlorohydrocarbons to chlorinated solvents used to clean instrument components prior to flight (Biemann et al., 1977).

Post-Viking studies have led to the recognition of chlorine across Mars (Keller et al., 2006) and the convincing detection of perchlorate in the northern latitudes of Mars by the Phoenix lander (Kounaves et al., 2010). Thermal decomposition of perchlorate and subsequent chlorination of indigenous organic carbon has received support as a plausible

Impacts and Astromaterials Research Centre, Department of Earth Science and Engineering, Imperial College London, London, UK. 
mechanism for the chlorohydrocarbons observed on Mars (Navarro-González et al., 2010). If we accept the almost universal presence of confounding mineralogies on Mars, it could be proposed that the correct instrumental response for the presence of indigenous organic carbon in surface materials is chlorohydrocarbons and the associated release of oxygen and carbon dioxide. Hence, Mars science is currently in the position that organic carbon has been detected at three landing sites (Chryse Planitia for Viking 1, Utopia Planitia for Viking 2, and Gale Crater for MSL), although in each case a definitively indigenous source of the organic carbon could not be confirmed. Intuitive thought suggests that we have repeatedly and frustratingly ascended to a level of confidence that is less than conclusive on a number of separate occasions and that future progress can only be achieved by a much superior experiment with greater definitiveness.

\section{Bayesian Statistics and Mars Data}

\subsection{Bayesian statistics}

Intuitive interpretations, however, ignore the influence of key statistical considerations: the intrinsic definitiveness of a test, the prior probability that indigenous organic matter is present in the sample, and the effects of cumulative experiments. Bayesian statistical approaches (Bayes, 1763; Sivia and Skilling, 2006) have revealed that absolute certainty is unnecessary and in fact is impossible, that the choice of sample has an influence on statistical certainty, and that repeated measurements can change the probability of indigenous organic carbon. The utility of Bayesian statistics on the detection of organic matter in asteroid and meteorite materials has already been demonstrated (Carter and Sephton, 2013). A correct organic detection experiment for Mars will involve treating a series of measurements that have detected organic carbon with incomplete definitiveness as a single large experiment. We can illustrate the impact of multiple partly conclusive measurements on Mars using Bayesian statistics where Mars data can be accommodated by the following equation

$$
P(L \mid T, I)=\frac{1}{1+\frac{P(T \mid \sim L, I)}{P(T \mid L, I)} \frac{(1-P(L \mid I))}{P(L \mid I)}}
$$

where

- $L$ is the presence of indigenous organic carbon

- $T$ is a positive measurement result

- $P(L \mid T, I)$ is the probability of indigenous organic carbon given a positive measurement result

- $P(L \mid I)$ is the probability of indigenous organic carbon prior to any measurement (i.e., the prior probability)

- $P(T \mid L, I)$ is the probability of a positive measurement result given that there is indigenous organic carbon (i.e., a true positive)

- $P(T \mid \sim L, I)$ is the probability of a positive measurement result given that there is no indigenous organic carbon (i.e., a false positive)

\subsection{Three key probabilities}

To determine the probability of indigenous organic carbon on Mars following the detection of chlorohydrocarbons, values for the following three probabilities need to be assigned:
- $P(L \mid I)$ the prior probability

- $P(T \mid L, I)$ the true positive

- $P(T \mid \sim L, I)$ the false positive

The prior probability represents the likelihood that indigenous organic carbon is present in the target sample on Mars before any measurements are made. The true positive is the probability that the measurement detected organic carbon as a result of indigenous organic carbon being present in the sample on Mars. The false positive is the probability that the measurement detected organic carbon despite the fact that indigenous organic carbon was not present on Mars before the measurement took place. For simplicity, the true positive and false positive can be combined into a single ratio. The true positive to false positive ratio is a key component for successful missions. If organic carbon is detected by a method with a true positive to false positive ratio that is greater than one, then the probability of indigenous organic carbon is increased relative to the prior probability. Each subsequent detection of organic carbon will lead to a progressive increase in the probability of indigenous organic carbon being present. The converse is also the case, and an organic carbon detection method with a true positive to false positive ratio that is less than one produces increasing uncertainty that the organic carbon is indigenous with each additional detection. Moreover, for a fixed number of analyses, the higher the true positive to false positive ratio, the higher the probability provided by a positive detection. Similar statistical approaches have been used in the field of medicine (e.g., Dujardin et al., 1994), but despite their importance, true positive to false positive ratios are never reported for Mars instruments. We will explore the effects of different true positive to false positive ratios below to demonstrate the benefits of methods or instruments with the highest possible true positive to false positive ratios.

\section{True Positive to False Positive Ratios}

The value for the true positive to false positive ratio can be obtained by Earth-based measurements such as those made on Mars analog samples. A value of zero or one, for either the true positive or the false positive, is not realistic. The ratio of true positives to false positives expresses the accuracy of the test when organic carbon is detected. False positives can be related to analytical artifacts, confounding mineralogies, or contamination. Analytical artifacts are those features that derive from the analytical procedure itself to produce signals. The degradation of organic instrument components or reagents can mimic the presence of indigenous organic carbon. Organic signals can also be generated by reactions generated in the sample during analysis. Certain minerals can decompose to produce organic matter (McCollom, 2003), while others may produce highly reactive species that interact with instrumental carbon. Contamination is also a means for producing false positives (Sephton et al., 2001). Avoidance of contamination of any sort is extremely difficult. Contamination can be carried forward to in situ analyses, and many more opportunities for contamination occur when samples are returned to Earth. Practical avoidance of contamination involves restricting contamination to sensitivities and/or resolutions that are undetectable by the destined analytical technique or techniques. If contamination is detectable, then it can be recognized and subsequently 
discounted when analytical signals are distinct from those in controls or blanks. Only contamination that can be confused with indigenous materials will represent a false positive.

In the context of missions to detect organic chemical responses, planetary protection is an important aspect of contamination control and, therefore, true positive to false positive ratios. Hence, different categories of planetary protection can have an impact on the true positive to false positive ratios. Surface missions that target special regions on Mars have more stringent requirements than those destined for elsewhere on the Red Planet (e.g., Frick et al., 2014), and the latter could have higher background levels of contamination and therefore lower true positive to false positive ratios. Another form of interference that can reduce certainty in instrument measurements is the presence of background noise. Higher sensitivities can lead to an increased response from the diagnostic portion of the signal relative to background noise. Signal-to-noise ratios above 3 and 10 are commonly used to indicate levels of detection and quantitation, respectively. If the background noise remains constant, the higher-sensitivity instruments considered for Mars (Mustard et al., 2013) can increase the true positive to false positive ratio and therefore the definitiveness of the method. Because the value for the true positive to false positive ratio is related only to the instrument measurement itself, the completion of preparatory work on a suitable variety of analog materials can generate reasonable values prior to mission operation.

The consequences of multiple partly conclusive measurements on the probabilities of indigenous organic carbon in Mars samples can be explored by using example data. Table 1 gives the number of measurements required to reach a given probability level from two different ratios of true positives to false positives, $0.11 / 0.10$ (a relatively poorly diagnostic test) and $0.20 / 0.10$ (a relatively highly diagnostic test). Table 1 reveals that, assuming a true positive to false positive ratio greater than one, more measurements give higher probabilities and that, for a fixed number of measurements, higher ratios of true positives to false positives give higher overall probabilities. It is clear that prelaunch effort expended on obtaining instrumental methods that have the highest possible true positive to false positive ratios is rewarded during analysis on Mars, especially when individual measurements are not completely conclusive. If further certainty is required, multiple mea- surements can be used to enhance the probability of indigenous organic carbon.

\section{Prior Probabilities}

\subsection{Generating prior probabilities}

The value for the prior probability can be obtained from previous campaigns that revealed the fraction of samples with confirmed indigenous organic carbon; unfortunately, no completely successful organic detection event exists for Mars. Another means is to rely on reasoning derived from scientific knowledge such as geological evidence of the history of Mars and its past and present similarities to conditions that produced organic matter-containing rocks on Earth. For a fixed number of analyses, organic matter detection in a sample with a higher prior probability of indigenous organic carbon will attract a greater level of certainty. Intuition might suggest that samples with low and high prior probabilities of indigenous organic carbon would provide a contrast of presence and absence to test the instrument. But Bayesian statistics indicate that, if resources are limited and the number of possible measurements low, then samples with the highest prior probabilities should be targeted and low prior probability samples avoided (Table 1). Samples on Mars with high or low prior probabilities can be recognized by the following characteristics:

\subsection{Age}

Early Mars and Earth experienced similar conditions, and they both had dense carbon dioxide atmospheres, oceans of liquid water, magnetic fields, and active volcanism. The climates of Mars and Earth diverged when the cooling interior of Mars led to a reduction in volcanism, loss of the planetary magnetic field, and diminishment of the martian atmosphere (Carr and Head, 2010). If we assume that the origin of life is a natural chemical consequence of a habitable environment, time, and the presence of requisite organic and inorganic starting materials, then the similarity between early Earth and Mars implies common timescales for the development of life. Early biospheres on the two planets would only differ when habitable conditions deteriorated on Mars. There is geochemical evidence for life on Earth at or before $3.8 \mathrm{Ga}$, firm multidisciplinary evidence for its existence before $3.4 \mathrm{Ga}$, and conclusive evidence for

Table 1. Number of Measurements Needed to Obtain Various Probabilities of Indigenous Carbon for Two Different Ratios of True Positives to False Positives and a Range of Prior Probabilities

\begin{tabular}{|c|c|c|c|c|c|c|c|c|c|c|c|}
\hline \multirow[b]{2}{*}{ Habitability } & \multirow[b]{2}{*}{ Prior } & \multicolumn{5}{|c|}{$\begin{array}{c}\text { (a) Probability of indigenous carbon for a } \\
\text { test with a true positive to false positive } \\
\text { ratio of } 0.1110 .10\end{array}$} & \multicolumn{5}{|c|}{$\begin{array}{c}\text { (b) Probability of indigenous carbon for } \\
\text { a test with a true positive to false positive } \\
\text { ratio of } 0.20 / 0.10\end{array}$} \\
\hline & & $\mathrm{p}=0.5$ & $\mathrm{p}=0.9$ & $\mathrm{p}=0.99$ & $\mathrm{p}=0.999$ & $\mathrm{p}=0.9999$ & $\mathrm{p}=0.5$ & $\mathrm{p}=0.9$ & $\mathrm{p}=0.99$ & $\mathrm{p}=0.999$ & $\mathrm{p}=0.9999$ \\
\hline \multirow[t]{5}{*}{ Low } & 0.01 & 49 & 72 & 97 & 121 & 144 & 7 & 10 & 14 & 17 & 20 \\
\hline & 0.1 & 24 & 47 & 72 & 96 & 120 & 4 & 7 & 10 & 14 & 17 \\
\hline & 0.2 & 15 & 38 & 63 & 88 & 112 & 2 & 6 & 9 & 12 & 16 \\
\hline & 0.5 & & 24 & 49 & 73 & 97 & & 4 & 7 & 10 & 14 \\
\hline & 0.8 & & 9 & 34 & 58 & 83 & & 2 & 5 & 8 & 12 \\
\hline High & 0.9 & & & 26 & 50 & 74 & & & 4 & 7 & 11 \\
\hline
\end{tabular}


Table 2. Target Rock Characteristics and Suggested Individual Prior Probabilities OF CONTAINING Indigenous CARBON

\begin{tabular}{lcc}
\hline Characteristic & \multicolumn{1}{c}{ High prior probability } & Low prior probability \\
\hline Age & Noachian $(\sim 0.4)$, early Hesperian $(\sim 0.3)$ & Late Hesperian $(\sim 0.2)$, Amazonian $(\sim 0.1)$ \\
Habitability & Mudstones $(\sim 0.4)$, hydrothermal deposits & Igneous rocks $(\sim 0.1)$, eolian rocks $(\sim 0.0)$ \\
& $(\sim 0.3)$, salts $(\sim 0.2)$ & \\
Preservation & Fine grained $(\sim 0.4)$, optimal sedimentation & No hydrological segregation $(\sim 0.05)$, \\
potential & rate $(\sim 0.25)$, hydrological segregation & sub-optimal sedimentation rate that is too \\
& $(\sim 0.2)$ & slow or too fast $(\sim 0.1)$, coarse-grained $(\sim 0.0)$ \\
Depth & Deep $(\geq 2 \mathrm{~m})$ sample $(\sim 0.4)$, moderate-depth & Shallow subsurface sample $(\sim 0.2)$, surface \\
& sample $(\sim 0.3)$ & sample $(\sim 0.1)$
\end{tabular}

All prior probabilities assume that indigenous organic matter is present somewhere on Mars, so prior probabilities in each row must sum to one.

its presence at $1.9 \mathrm{Ga}$ (Knoll, 2003). Following the loss of the majority of the martian atmosphere, life may have persisted in refugia perhaps up to the present day, but the probability of present-day life is much smaller than that of ancient life. Consequently, the prior probability of detecting indigenous organic carbon is highest in the oldest (Noachian and early Hesperian) rocks and lowest in the most recent (Amazonian) rocks (Table 2). Noachian rocks cover about $40 \%$ of the martian surface (Barlow, 1988), mostly in the southern hemisphere (Watters et al., 2007).

\subsection{Habitability}

For indigenous organic carbon derived from life to be present, an environment must have existed that is conducive to habitation. Habitability is most obviously indicated by rocks that provide evidence of liquid water. Water-influenced rocks include subaqueous sediments, hydrothermal sediments, hydrothermally altered rocks, and low-temperature fluid-altered rocks (Summons et al., 2011). The prior probability of detecting indigenous organic carbon is, therefore, highest in deposits that reflect the influence of liquid water and lowest in rocks that do not. An example related to habitability variations on a local scale is provided by recent data from MSL. The MSL mission recognized a higher abundance of potentially organic carbon-derived carbon dioxide in water-lain mudstones (Leshin et al., 2013) and a lower abundance in water-free eolian deposits (Ming et al., 2014). Habitability can also be assessed on a global scale where the abundance of hydrated minerals is related to age. Evidence of liquid water is found primarily in Noachian terrains (Poulet et al., 2005), and it appears that the Noachian crust was altered homogeneously across the planet (Carter et al., 2010). Some widespread water may have persisted until the late Noachian through to the early Hesperian when volcanic sulfates turned surface conditions acidic (Bibring et al., 2006). Therefore, the age-based arguments discussed above for the origin and persistence of life also apply to habitability on a global scale, with older rocks attracting a higher prior probability and younger rocks having a lower prior probability of indigenous organic carbon (Table 2).

\subsection{Preservation}

The successful detection of indigenous organic carbon relies on preservation of its signals in rocks. Proposed factors that influence preservation on Earth and may also have an effect on Mars include hydrological segregation and concentration, sediment grain size, sediment accumulation rate, and presence or absence of oxidants. Certain martian environments will preserve autochonous organic matter, for example where standing bodies of water have hosted life from which organic remains have settled without transport. Other environments receive allochthonous organic matter from a hinterland following transport from distant habitats. Advantages exist for transported sediments because the hydrological properties of organic matter allow its segregation and concentration (e.g., Tyson, 1995). Erosion rates and therefore hydrological segregation and concentration opportunities were greatest in the early history of Mars and reduced noticeably following the Noachian (Carr and Head, 2010). The hydrological selection of organic matter can lead to its accumulation in specific depositional environments, and rocks generated in such locations will have high prior probabilities of indigenous organic carbon (Table 2).

\subsection{Sediment grain size}

Organic matter contents correlate with fine-grained sediments because of multiple mechanisms. Fine-grained minerals and low-density organic particles have similar hydrodynamic properties and are deposited together. Once deposited, mixtures of organic matter and fine-grained minerals often produce a low-porosity matrix, which allows limited access to electron acceptors that induce oxidation. Adsorption of organic matter onto fine-grained minerals, especially those with large surface areas, also reduces opportunities for degradation and promotes polymerization reactions that produce more intractable organic structures (Weiler and Mills, 1965; Tanoue and Handa, 1979). Therefore, samples comprising fine-grained sedimentary materials will have higher prior probabilities of indigenous organic carbon (Table 2).

\subsection{Sediment accumulation rate}

Sediment accumulation rate can control organic preservation. On Earth, degradation activities decrease with depth owing to higher concentrations of more potent electron acceptors near the surface. The surface of Mars is also highly oxidized (Klein, 1978) owing to intense UV radiationdriven photochemistry that produces strongly oxidizing species that react with the regolith (Hunten, 1979). Surface oxidants could diffuse into the subsurface and degrade subsurface organic matter. Concentrations of the likely oxidant 
hydrogen peroxide will decline with depth, and for reasonable suggested lifetimes the maximum diffusion depth is less than 2.3 m (Bullock et al., 1994).

Rapid deposition will transport organic matter out of the degradation zone before complete loss has occurred (Henrichs, 1992). Within a range of sediment burial rates of $0.1-10 \mathrm{mg} \mathrm{cm}^{-2} \mathrm{yr}^{-1}$, the organic carbon content of sediments doubles with each 10-fold increase in sedimentation rate (Müller and Suess, 1979). Below sediment accumulation rates of $0.1 \mathrm{mg} \mathrm{cm}^{-2} \mathrm{yr}^{-1}$, most organic matter is lost through degradation; and above rates of $10 \mathrm{mg} \mathrm{cm}^{-2} \mathrm{yr}^{-1}$, concentrations level off (Hedges and Keil, 1995). Eventually, higher rates will lead to dilution of organic contents (Müller and Suess, 1979). The optimum sediment accumulation rates on Earth correspond to clay-rich shales or relatively slowly accumulating tidal flats and deltas (Einsele, 1992), and similar target environments on Mars can be considered as having high prior probabilities for indigenous organic carbon preservation (Table 2).

\subsection{Depth}

Organic carbon concentration may be dependent on depth owing to surface supply of oxidants mentioned above but also the influence of ionizing radiation. It is suggested that radiation-induced oxidation extends to greater depths than percolating oxidants (Kminek and Bada, 2006). Total radiation types at the surface of Mars comprise UV, solar energetic particles, and galactic cosmic rays. UV photons are limited to a penetration of just a few micrometers, solar energetic particles $10 \mathrm{~cm}$, and galactic cosmic rays up to $3 \mathrm{~m}$ (Parnell et al., 2007). If we consider martian rocks that record activity when the planet was most habitable, then amino acid data reveal that some organic matter will be preserved at $0.75 \mathrm{~m}\left(f=c a .1 \times 10^{-12}\right), 1 \mathrm{~m}\left(f=c a .1 \times 10^{-9}\right)$, and $1.5 \mathrm{~m}\left(f=c a .1 \times 10^{-3}\right)$, and with all organic matter $(f=1)$ preserved at $3 \mathrm{~m}$ (Kminek and Bada, 2006). Samples from greater depths will, therefore, have high prior probabilities of indigenous organic carbon contents (Table 2).

\subsection{Using prior probabilities}

Table 1 gives the number of measurements required to reach a given probability level from prior probabilities that are varied from 0.01 (poorly habitable) to 0.9 (eminently habitable) paleoenvironments and the levels of certainty (0.50.9999) associated with specific numbers of measurements. Data in Table 1 reveal that for a fixed number of measurements higher prior probabilities give more certainty. If the number of analyses on Mars is limited, then samples with the very highest prior probabilities will be needed to achieve the best levels of certainty. Understanding the potential for different rock types on Mars to produce and preserve indigenous organic carbon, by the study of analog materials on Earth, is also a valuable exercise that can help in targeting samples and the interpretation of any analytical data obtained.

\section{Interpreting Past, Present, and Future Measurements on Mars}

The true positive to false positive ratio is essential for assessing whether a method will effectively identify indigenous organic matter on Mars. Yet the true positive to false positive ratio is rarely, if ever, reported for techniques destined for the Red Planet. The true positive to false positive ratio should be determined by the extensive testing of analog materials on Earth. Testing on Earth of Mars analogues with perchlorate and other Mars-relevant minerals with variable organic matter contents would reveal the true positive to false positive ratio associated with indigenous organic matter when chlorohydrocarbons are detected. If the true positive to false positive ratio is above one, then repeated measurements lead to greater confidence that indigenous organic matter is present. The prior probability of the target rock is also a valuable consideration when confidence of the indigeneity of detected organic carbon is required. Organic matter detection in a higher prior probability sample will produce a greater likelihood of indigenous organic carbon.

We can examine the benefits provided by a Bayesian statistical approach compared to intuition when operating on Mars. When provided with a difficult question, intuition provides an answer to a less complex question without the substitution being recognized (Kahneman, 2011). For instance, when presented with the real question on MarsWhat is the best combination of target samples if true and false positives and negatives are being produced?-our intuition substitutes an answer to the relatively simple question-What is the best combination of target samples if only true positives and true negatives are being produced? For further illustration, we can consider some sample types that could be encountered by an organic carbon-detection mission to Mars. An eolian sample (Leshin et al., 2013) would present a sample with a low prior probability of indigenous organic carbon, while a mudstone sample (Ming et al., 2014) would present a sample with a high prior probability of indigenous organic carbon. It is notable that during the MSL mission eolian and mudstone samples have produced organic matter of uncertain origin when analyzed. We assume that the true positive to false positive ratio for an MSL-type gas chromatograph-mass spectrometer instrument analyzing these samples is greater than one. For a fixed number of analyses, a higher certainty of indigenous organic carbon will be achieved if all analyses take place on the mudstones. Multiple positive measurements of organic carbon in higher prior probability samples increase the likelihood that the organic carbon is indigenous. Yet intuition encourages us to choose samples with contrasting prior probabilities of indigenous organic carbon despite the fact that multiple positive measurements of organic carbon in samples of variable prior probabilities will produce a lesser probability that the organic carbon is indigenous. Hence, a statistical approach is needed to avoid the highly tempting bias produced by intuition. The characteristics related to higher prior probabilities of indigenous organic carbon (Table 1) can be applied to individual samples at smaller scales but also to wider regions on Mars (Fig. 1).

Our Bayesian statistical considerations provide optimism for future, more complex mission designs, such as Mars Sample Return (McLennan et al., 2012). Preparation for returned samples will help identify samples with higher prior probabilities of indigenous organic carbon. A lack of certainty can be overcome with better tests and multiple measurements, all of which will be available once samples are back on Earth to provide an accelerated means of 
FIG. 1. Three areas of Mars with different prior probabilities of indigenous carbon. (A) Nili Fossae contains Noachian fine-grained phyllosilicates deposited or produced by liquid water. Samples from this location would have high prior probabilities of indigenous organic carbon, and prior probabilities would be highest in samples obtained from depth. (B) Valles Marineris contains Hesperian salts (with hydrated silicates) produced by the evaporation of water. Samples from the salts would have a medium prior probability of indigenous organic carbon. (C) Proctor Crater contains Amazonian sand dunes produced by eolian processes. Samples from this location would have low prior probabilities of indigenous organic carbon, and prior probabilities would be lowest in samples obtained from the surface. All images from NASA/JPL/University of Arizona. Color images available online at www .liebertonline.com/ast
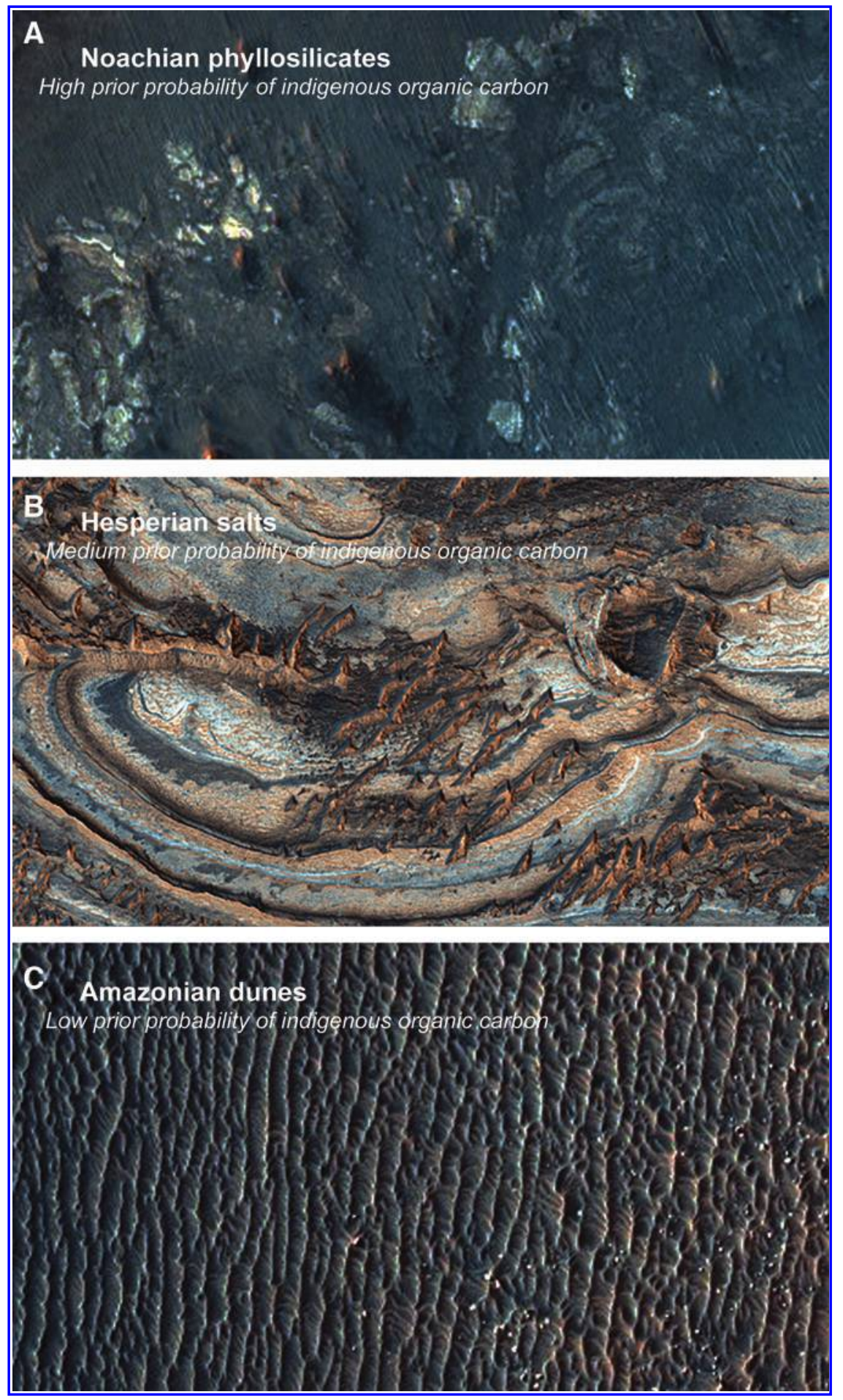

achieving statistical certainty of indigenous organic carbon on Mars.

\section{Conclusions}

Organic carbon has been detected on Mars repeatedly, but its indigenous nature remains uncertain. The accumulated data set is complicated by confounding minerals. When faced with complex data sets, intuition prompts interpretations and decisions that are not statistically supported. In such situations, incorrect samples can be chosen, good data can be discarded, and discoveries can be missed. Bayesian statistics provide guidance for the planning and operation of organic carbon detection on Mars. For an instrumental method that has a true positive to false positive ratio greater than one, the repeated detection of organic matter progressively increases the probability that the organic carbon is indigenous. For a fixed number of measurements, organic matter detection by methods with higher ratios of true positives to false positives will give higher overall probabilities. 
For a fixed number of analyses, organic matter detection in samples with higher prior probabilities of indigenous organic carbon will attract a greater overall level of certainty. Contrasts of likely indigenous organic carbon-rich and indigenous organic carbon-poor samples are less valuable than multiple measurements on samples with high prior probabilities of indigenous organic carbon. If resources are limited and the number of possible measurements low, then samples with the highest prior probabilities should be targeted and low prior probability samples avoided. Choosing samples on Mars with the highest prior probabilities of indigenous organic carbon is a subjective process, but such samples are likely to be ancient (e.g., Noachian), produced or deposited in the presence of liquid water, composed of fine-grained material, deposited during sedimentation rates similar to those of clayrich shales or slowly accumulating deltas, and recovered from depths of several meters.

\section{Acknowledgments}

The authors are grateful for the constructive and highly useful comments of three anonymous reviewers.

\section{Author Disclosure Statement}

The authors state that no competing financial interests exist.

\section{Abbreviation}

MSL, Mars Science Laboratory.

\section{References}

Barlow, N.G. (1988) The ridged plains as a possible landing site for the Mars sample return mission. In Workshop on Mars Sample Return Science, edited by M.J. Drake, R. Greeley, G.A. McKay, D.P. Blanchard, M.H. Carr, J.L. Gooding, C.P. McKay, P.D. Spudis, and S.W. Squyres, Lunar and Planetary Institute, Houston, pp 37-38.

Bayes, T. (1763) An essay towards solving a problem in the doctrine of chances. Philosophical Transactions of the Royal Society of London 53:370-418.

Bibring, J.-P., Langevin, Y., Mustard, J.F., Poulet, F., Arvidson, R., Gendrin, A., Gondet, B., Mangold, N., Pinet, P., Forget, F., and the OMEGA Team. (2006) Global mineralogical and aqueous Mars history derived from OMEGA/Mars Express data. Science 312:400-404.

Biemann, K., Oro, J., Toulmin, P., III, Orgel, L.E., Nier, A.O., Anderson, D.M., Flory, D., Diaz, A.V., Rushneck, D.R., and Simmonds, P.G. (1977) The search for organic substances and inorganic volatile compounds in the surface of Mars. $\underline{J}$ Geophys Res 82:4641-4658.

Bullock, M.A., Stoker, C.R., McKay, C.P., and Zent, A.P. (1994) Coupled soil-atmosphere model of $\mathrm{H}_{2} \mathrm{O}_{2}$ on Mars. Icarus 107:142-154.

Carr, M.H. and Head, J.W. (2010) Geologic history of Mars. Earth Planet Sci Lett 294:185-203.

Carter, J., Poulet, F., Bibring, J.-P., and Murchie, S. (2010) Detection of hydrated silicates in crustal outcrops in the northern plains of Mars. Science 328:1682-1686.

Carter, J.N. and Sephton, M.A. (2013) A Bayesian statistical assessment of representative samples for asteroidal or meteoritical material. Meteorit Planet Sci 48:976-996.
Dujardin, B., Ende, J., Gompel, A., Unger, J.-P., and Stuyft, P. (1994) Likelihood ratios: a real improvement for clinical decision making? Eur J Epidemiol 10:29-36.

Einsele, G. (1992) Sedimentary Basins: Evolution, Facies, and Sediment Budget, Springer, Berlin.

Frick, A., Mogul, R., Stabekis, P., Conley, C.A., and Ehrenfreund, P. (2014) Overview of current capabilities and research and technology developments for planetary protection. Adv Space Res 54:221-240.

Hedges, J.I. and Keil, R.G. (1995) Sedimentary organic matter preservation: an assessment and speculative synthesis. $\underline{\text { Mar }}$ Chem 49:81-115.

Henrichs, S.M. (1992) Early diagenesis of organic matter in marine sediments: progress and perplexity. Mar Chem 39:119-149.

Hunten, D. (1979) Possible oxidant sources in the atmosphere and surface of Mars. J Mol Evol 14:71-78.

Kahneman, D. (2011) Thinking, Fast and Slow, Farrar, Straus and Giroux, New York.

Keller, J.M., Boynton, W.V., Karunatillake, S., Baker, V.R., Dohm, J.M., Evans, L.G., Finch, M.J., Hahn, B.C., Hamara, D.K., Janes, D.M., Kerry, K.E., Newsom, H.E., Reedy, R.C., Sprague, A.L., Squyres, S.W., Starr, R.D., Taylor, G.J., and Williams, R.M.S. (2006) Equatorial and midlatitude distribution of chlorine measured by Mars Odyssey GRS. J Geophys Res Planets 111, doi:10.1029/2006JE002679.

Klein, H.P. (1978) The Viking biological experiments on Mars. Icarus 34:666-674.

Kminek, G. and Bada, J.L. (2006) The effect of ionizing radiation on the preservation of amino acids on Mars. Earth Planet Sci Lett 245:1-5.

Knoll, A.H. (2003) Life on a Young Planet, Princeton University Press, Princeton, NJ.

Kounaves, S.P., Hecht, M.H., Kapit, J., Gospodinova, K., DeFlores, L., Quinn, R.C., Boynton, W.V., Clark, B.C., Catling, D.C., Hredzak, P., Ming, D.W., Moore, Q., Shusterman, J., Stroble, S., West, S.J., and Young, S.M.M., (2010) Wet Chemistry experiments on the 2007 Phoenix Mars Scout Lander mission: data analysis and results. J Geophys Res Planets 115, doi:10.1029/2009JE003424.

Leshin, L.A., Mahaffy, P.R., Webster, C.R., Cabane, M., Coll, P., Conrad, P.G., Archer, P.D., Atreya, S.K., Brunner, A.E., Buch, A., Eigenbrode, J.L., Flesch, G.J., Franz, H.B., Freissinet, C., Glavin, D.P., McAdam, A.C., Miller, K.E., Ming, D.W., Morris, R.V., Navarro-González, R., Niles, P.B., Owen, T., Pepin, R.O., Squyres, S., Steele, A., Stern, J.C., Summons, R.E., Sumner, D.Y., Sutter, B., Szopa, C., Teinturier, S., Trainer, M.G., Wray, J.J., Grotzinger, J.P., and the MSL Science Team. (2013) Volatile, isotope, and organic analysis of martian fines with the Mars Curiosity rover. Science 341, doi:10.1126/science.1238937.

McCollom, T.M. (2003) Formation of meteorite hydrocarbons from thermal decomposition of siderite $\left(\mathrm{FeCO}_{3}\right)$. Geochim Cosmochim Acta 67:311-317.

McLennan, S.M., Sephton, M.A., Allen, C., Allwood, A.C., Barbieri, R., Beaty, D.W., Boston, P., Carr, M., Grady, M., Grant, J., Heber, V.S., Herd, C.D.K., Hofmann, B., King, P., Mangold, N., Ori, G.G., Rossi, A.P., Raulin, F., Ruff, S.W., Sherwood Lollar, B., Symes, S., and Wilson, M.G. (2012) Planning for Mars returned sample science: final report of the MSR End-to-End International Science Analysis Group (E2E-iSAG). Astrobiology 12:175-230.

Ming, D.W., Archer, P.D., Glavin, D.P., Eigenbrode, J.L., Franz, H.B., Sutter, B., Brunner, A.E., Stern, J.C., Freissinet, C., McAdam, A.C., Mahaffy, P.R., Cabane, M., Coll, P., 
Campbell, J.L., Atreya, S.K., Niles, P.B., Bell, J.F., Bish, D.L., Brinckerhoff, W.B., Buch, A., Conrad, P.G., Des Marais, D.J., Ehlmann, B.L., Fairén, A.G., Farley, K., Flesch, G.J., Francois, P., Gellert, R., Grant, J.A., Grotzinger, J.P., Gupta, S., Herkenhoff, K.E., Hurowitz, J.A., Leshin, L.A., Lewis, K.W., McLennan, S.M., Miller, K.E., Moersch, J., Morris, R.V., Navarro-González, R., Pavlov, A.A., Perrett, G.M., Pradler, I., Squyres, S.W., Summons, R.E., Steele, A., Stolper, E.M., Sumner, D.Y., Szopa, C., Teinturier, S., Trainer, M.G., Treiman, A.H., Vaniman, D.T., Vasavada, A.R., Webster, C.R., Wray, J.J., Yingst, R.A., and the MSL Science Team. (2014) Volatile and organic compositions of sedimentary rocks in Yellowknife Bay, Gale Crater, Mars. Science 343 doi:10.1126/science.1245267.

Müller, P.J. and Suess, E. (1979) Productivity, sedimentation rate, and sedimentary organic matter in the oceans-I. Organic carbon preservation. Deep Sea Res A 26:1347-1362.

Mustard, J.F., Adler, M., Allwood, A., Bass, D.S., Beaty, D.W., Bell, J.F., Brinckerhoff, W.B., Carr, M., Des Marais, D.J., Drake, B., Edgett, K.S., Eigenbrode, J., Elkins-Tanton, L.T., Grant, J.A., Milkovich, S.M., Ming, D., Moore, C., Murchie, S., Onstott, T.C., Ruff, S.W., Sephton, M.A., Steele, A., and Treiman, A. (2013) Report of the Mars 2020 Science Definition Team, posted July 2013 by the Mars Exploration Program Analysis Group (MEPAG). Available online at http://mepag.jpl.nasa.gov/reports/ MEP/Mars_2020_SDT_Report_Final.pdf.

Navarro-González, R., Vargas, E., de la Rosa, J., Raga, A.C., and McKay, C.P. (2010) Reanalysis of the Viking results suggests perchlorate and organics at midlatitudes on Mars. $J$ Geophys Res Planets 115, doi:10.1029/2010JE003599.

Parnell, J., Cullen, D., Sims, M., Bowden, S., Cockell, C., Court, R., Ehrenfreund, P., Gaubert, F., Grant, B., Parro, V., Rohmer, M., Sephton, M., Stan-Lotter, H., Steele, A., Toporski, J., and Vago, J. (2007) Searching for life on Mars: selection of molecular targets for the ESA Aurora ExoMars mission. Astrobiology 7:578-604.

Poulet, F., Bibring, J.P., Mustard, J.F., Gendrin, A., Mangold, N., Langevin, Y., Arvidson, R.E., Gondet, B., and Gomez, C.
(2005) Phyllosilicates on Mars and implications for early martian climate. Nature 438:623-627.

Sephton, M.A., Pillinger, C.T., and Gilmour, I. (2001) Normal alkanes in meteorites: molecular $\delta^{13} \mathrm{C}$ values indicate an origin by terrestrial contamination. Precambrian Res 106: 47-58.

Sivia, D. and Skilling, J. (2006) Data Analysis: A Bayesian Tutorial, Oxford University Press, Oxford.

Summons, R.E., Amend, J.P., Bish, D., Buick, R., Cody, G.D., Des Marais, D.J., Dromart, G., Eigenbrode, J.L., Knoll, A.H., and Sumner, D.Y. (2011) Preservation of martian organic and environmental records: final report of the Mars Biosignature Working Group. Astrobiology 11:157-181.

Tanoue, E. and Handa, N. (1979) Differential sorption of organic matter by various sized sediment particles in recent sediment from the Bering Sea. Journal of the Oceanographical Society of Japan 35:199-208.

Tyson, R. (1995) Sedimentary Organic Matter: Organic Facies and Palynofacies, Chapman and Hall, London.

Watters, T.R., McGovern, P.J., and Irwin, R.P., III. (2007) Hemispheres apart: the crustal dichotomy on Mars. Annu Rev Earth Planet Sci 35:621-652.

Weiler, R.R. and Mills, A.A. (1965) Surface properties and pore structure of marine sediments. Deep Sea Research and Oceanographic Abstracts 12:511-529.

Address correspondence to: Mark A. Sephton Department of Earth Science and Engineering Imperial College London London SW7 2AZ

$U K$

E-mail: m.a.sephton@imperial.ac.uk

Submitted 23 February 2014 Accepted 3 June 2014 